Article

\title{
Lipopolysaccharide-Induced Nitric Oxide, Prostaglandin E2, and Cytokine Production of Mouse and Human Macrophages Are Suppressed by Pheophytin-b
}

\author{
Chun-Yu Lin ${ }^{1,2,3}$, Wen-Hung Wang ${ }^{1,3}$, Shin-Huei Chen ${ }^{2}$, Yu-Wei Chang ${ }^{2}$, Ling-Chien Hung ${ }^{1,3}$, \\ Chung-Yi Chen 4 (iD) and Yen-Hsu Chen 1,2,3,5,* \\ 1 Division of Infectious Diseases, Department of Internal Medicine, Kaohsiung Medical University Hospital, \\ Kaohsiung 807, Taiwan; infectionman@gmail.com (C.-Y.L.); bole0918@gmail.com (W.-H.W.); \\ lavender99kimo@yahoo.com.tw (L.-C.H.) \\ 2 Sepsis Research Center, Graduate Institute of Medicine, College of Medicine, Kaohsiung Medical University, \\ Kaohsiung 807, Taiwan; beautyhappy19@gmail.com (S.-H.C.); golden3p@gmail.com (Y.-W.C.) \\ 3 Research Center for Environmental Medicine, Kaohsiung Medical University, Kaohsiung 807, Taiwan \\ 4 School of Medical and Health Sciences, Fooyin University, Kaohsiung 831, Taiwan; XX377@fy.edu.tw \\ 5 Department of Biological Science and Technology, College of Biological Science and Technology, \\ National Chiao Tung University, Hsinchu 300, Taiwan \\ * Correspondence: infchen@gmail.com; Tel.: +886-7-312-1101 (ext. 5677)
}

Received: 30 October 2017; Accepted: 4 December 2017; Published: 6 December 2017

\begin{abstract}
Sepsis is an overwhelming systemic response to infection that frequently results in tissue damage, organ failure, and even death. Nitric oxide (NO), prostaglandin E2 (PGE2), and cytokine overproduction are thought to be associated with the immunostimulatory cascade in sepsis. In the present study, we analyzed the anti-inflammatory efficacy of the pheophytin-b on both RAW 264.7 murine macrophage and purified human $\mathrm{CD}_{1}{ }^{+}$monocytes stimulated with lipopolysaccharide (LPS) and elucidated the mechanisms by analyzing the cell signaling pathways known to be activated in sepsis. Pheophytin-b suppressed the overexpression of NO, PGE2, and cytokines in LPS-stimulated macrophages without inducing cytotoxicity. It also reduced NOS2 and COX-2 mRNA and protein levels. The inhibitory effects on NO, PGE2, and cytokine overproduction arose from the suppression of STAT-1 and PI3K/Akt pathways; no changes in NF-KB, MAPK, and AP-1 signaling were detected. Thus, pheophytin-b may represent a potential candidate to beneficially modulate the inflammatory response in sepsis.
\end{abstract}

Keywords: pheophytin-b; nitric oxide; prostaglandin E2; cytokine; macrophages; lipopolysaccharide

\section{Introduction}

Sepsis, severe sepsis, and septic shock remain to be the main causes of death among critically ill patients [1], and the number of new sepsis cases are increasing [2,3] despite advances in understanding its etiology and the development of new therapeutic strategies [4]. The management of severe sepsis is especially challenging because of its high mortality rate [5]. Despite improvements in the quality of critical care, the mortality rate of sepsis remains high, ranging from $18 \%$ to $50 \%[1,4,6]$. Although several immunomodulation and anticoagulation drugs have been developed to treat sepsis, their efficacies are limited, and some have been withdrawn from the market [3]. Therefore, the development of new agents that could be applied for the treatment of sepsis is critical $[7,8]$.

Microbial components are always potential stimulators for macrophage activation. Macrophage is the major effector of innate immune response, which associates with cytokines secretion, phagocytosis, 
and antigen presenting. Sepsis is known to be correlated with the imbalance between pro-inflammatory and anti-inflammatory [9]. Patients with sepsis exhibit heightened inflammatory responses, including nitric oxide (NO) production, cytokines secretion, and prostaglandin synthesis [10], which are thought to be induced at least in part by the endotoxin lipopolysaccharide (LPS) a major component of the cell walls of many Gram-negative sepsis-inducing microbes. LPS is demonstrated to influence thousands of cytokine-related genes expression in macrophage [11]. Additionally, excessive NO production during sepsis, which is mainly generated by NO synthase 2 (NOS2, also named inducible NO synthase) encoded by NOS2 gene [12], has been suggested to be one of the main factors leading to tissue injury induced by septic shock [13]. NO and overexpressed cytokines, such as tumor necrosis factor- $\alpha$ (TNF- $\alpha$ ), interleukin-1 $\beta$ (IL-1 $\beta$ ), and IL-6, were also shown to cause sepsis-related systemic inflammation [14] and myocardial depression in sepsis and septic shock [15-17]. Prostaglandin E2 (PGE2) is primarily synthesized by cyclooxygenase-2 (COX-2), which is also responsible for sepsis-related inflammatory symptoms and signs [18]. COX-2 can be overexpressed following stimulation with LPS [19].

We have previously found that pheophytin-a, which is a chlorophyll-related compound extracted from green tea, elicits anti-inflammatory effects [20]. Pheophytin-b, another chlorophyll-related compound, possesses medically beneficial properties, such as anti-tumor effects [21], anti-genotoxic effects [22], and anti-oxidative activity [23]. Pheophytin-a and pheophytin-b show the difference in the chemical structure C-7, where there is a methyl group in pheophytin-a and a formyl group in pheophytin- $b$. However, the precise role of pheophytin- $b$ in sepsis-related inflammation remains unknown. Therefore, in this study, we investigated the efficacy of pheophytin-b using the RAW 264.7 murine cell model as well as purified human CD14 ${ }^{+}$monocytes. Furthermore, we elucidated the molecular mechanisms by which pheophytin-b exerts its effects.

\section{Results}

\subsection{Pheophytin-b Does Not Induce Macrophage Cytotoxicity}

The chemical structure of pheophytin-b is illustrated in Figure 1A. As shown in Figure 1B, pheophytin-b did not influence the cell viability of RW264.7 cells in doses up to $50 \mu \mathrm{M}$. Similarly, analysis of human $\mathrm{CD}_{1} 4^{+}$monocyte-derived macrophages showed no significant change in macrophage viability upon treatment with pheophytin-b at doses up to $50 \mu \mathrm{M}$ (Figure 1C; the purity of human $\mathrm{CD}_{14}{ }^{+}$monocyte has been shown in Figure S1). Thus, all subsequent experiments used in the present study were performed using a maximal $50 \mu \mathrm{M}$ dose of pheophytin-b.

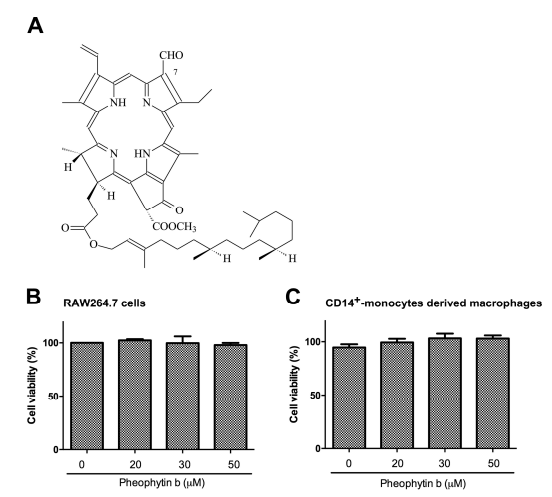

Figure 1. Pheophytin-b treatment had no significant effect on the viabilities of RAW 264.7 cells or human $\mathrm{CD}_{14}{ }^{+}$monocyte-derived macrophages. (A) Chemical structure of pheophytin-b. Both RAW 264.7 cells (B) and human CD14 ${ }^{+}$monocyte-derived macrophages (C) were treated with pheophytin-b for $24 \mathrm{~h}$ at the indicated concentrations and viabilities were measured using an Alamar Blue assay. Data are expressed as the means \pm standard deviations (SD) of five independent experiments $(n=5)$. 


\subsection{Effects of Pheophytin- $b$ on NO and PGE2 Production in LPS-Stimulated Macrophages}

In the present study, pre-treatment of RAW 264.7 cells with pheophytin-b for 30 min elicited significant, dose-dependent suppression of LPS-induced NO production as detected by a reduction in nitrite levels $(p<0.05$; Figure 2A). Furthermore, using an enzyme-linked immunosorbent assay (ELISA), pre-treatment with pheophytin-b significantly attenuated LPS-stimulated PGE2 production by RAW 264.7 cells also in a dose-dependent manner ( $p<0.05$; Figure 2B).

\section{A}

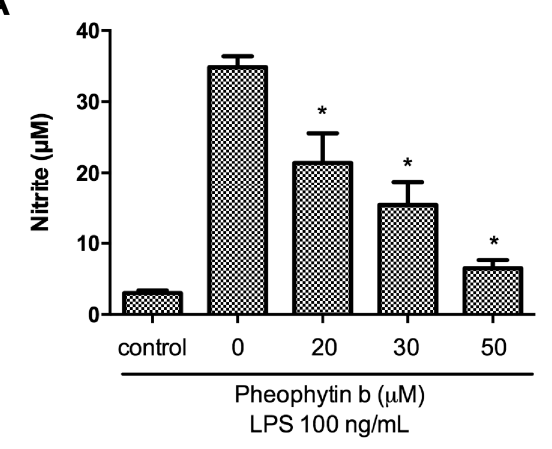

B

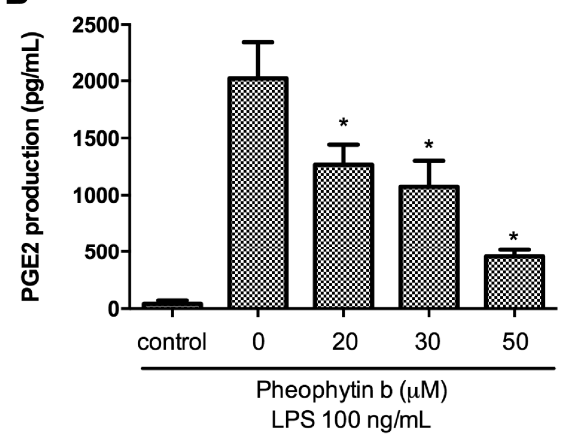

Figure 2. The pre-treatment with pheophytin-b exerted significant repression of LPS-induced NO and PGE2 production. RAW 264.7 cells were pre-treated with the indicated concentrations of pheophytin-b for $30 \mathrm{~min}$, and the production of nitrite (A) and PGE2 (B) were quantified after $6 \mathrm{~h}$ and $16 \mathrm{~h}$ of LPS $(100 \mathrm{ng} / \mathrm{mL})$ stimulation, respectively. ${ }^{*} p<0.05$ vs. LPS-treated cells (by Student's $t$-test, $n=3$ ).

\subsection{Effects of Pheophytin-b on NOS2 and COX-2 Expression}

LPS-induced expression of NOS2 protein and mRNA were also repressed in RAW 264.7 cells with pheophytin-b in a dose-dependent manner $(p<0.05$; Figures $3 \mathrm{~A}$ and $4 \mathrm{~A}$, respectively). Similarly, pre-treatment with pheophytin-b attenuated COX-2 gene expression in a dose-dependent manner, as indicated by decreased protein synthesis and mRNA levels $(p<0.05$; Figures $3 \mathrm{~B}$ and $4 \mathrm{~B}$, respectively).

\subsection{Effects of Pheophytin-b on Cytokine Production in LPS-Stimulated Macrophages}

We also analyzed the effects of pheophytin-b on cytokine production in LPS-stimulated RAW 264.7 cells. As shown in Figure 5, LPS increased TNF- $\alpha$, IL-6, IL-1 $\beta$, and IL-10 levels as compared to untreated controls; however, all of these cytokines were significantly decreased with $50 \mu \mathrm{M}$ pheophytin-b treatment (all $p<0.05)$.

2.5. Effects of Pheophytin-b on PGE2 and Cytokine Production in $C D 14^{+}$Monocyte-Derived Macrophages after LPS Stimulation

To confirm the anti-inflammatory effects of pheophytin-b on macrophages, we also used CD14 ${ }^{+}$ monocyte-derived macrophages to perform ex vivo experiments. As is shown in Figure 6, LPS-induced 
PGE2 and inflammatory cytokines were all suppressed by pheophytin-b. However, NO production in the supernatants of LPS-stimulated CD14 ${ }^{+}$monocyte-derived macrophages was near the limit of detection (data not shown) [24].
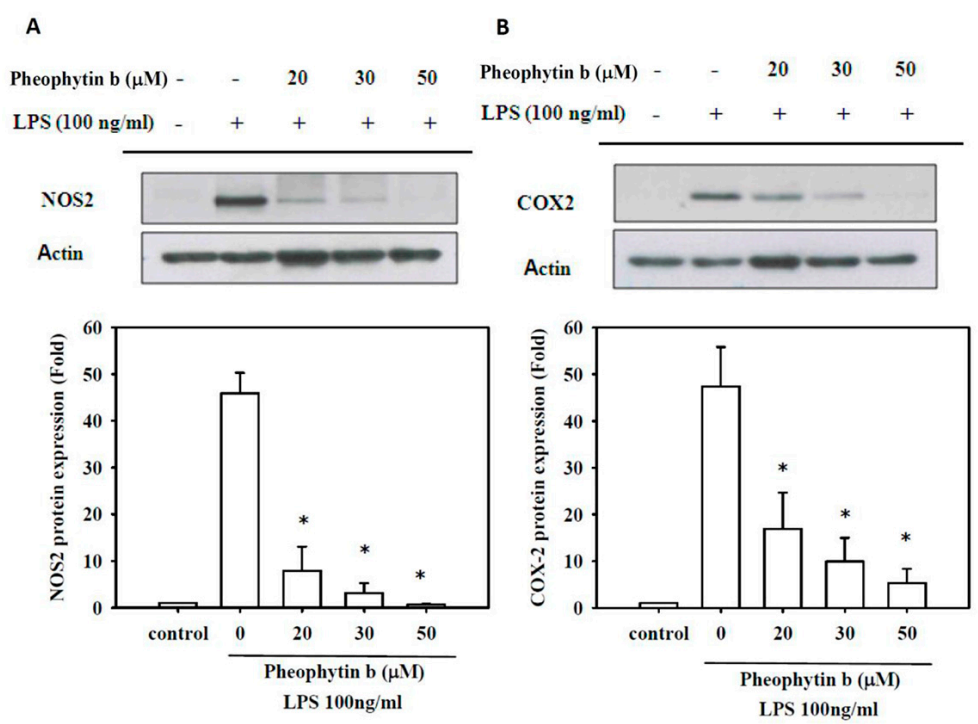

Figure 3. Pheophytin-b suppressed NOS2 and COX-2 protein synthesis in LPS-stimulated RAW 264.7 cells. Cells were pre-treated with the indicated concentrations of pheophytin-b for $30 \mathrm{~min}$ and stimulated with LPS for $6 \mathrm{~h}$. NOS2 (A) and COX-2 (B) protein levels were determined by Western blot analysis, quantified, and normalized to those of the control group. Bottom panels show the fold-change compared to the control group (without LPS stimulation). Actin levels were analyzed as a control to ensure equal loading. ${ }^{*} p<0.05$ vs. LPS-treated cells (by Student's $t$-test, $n=3$ ).

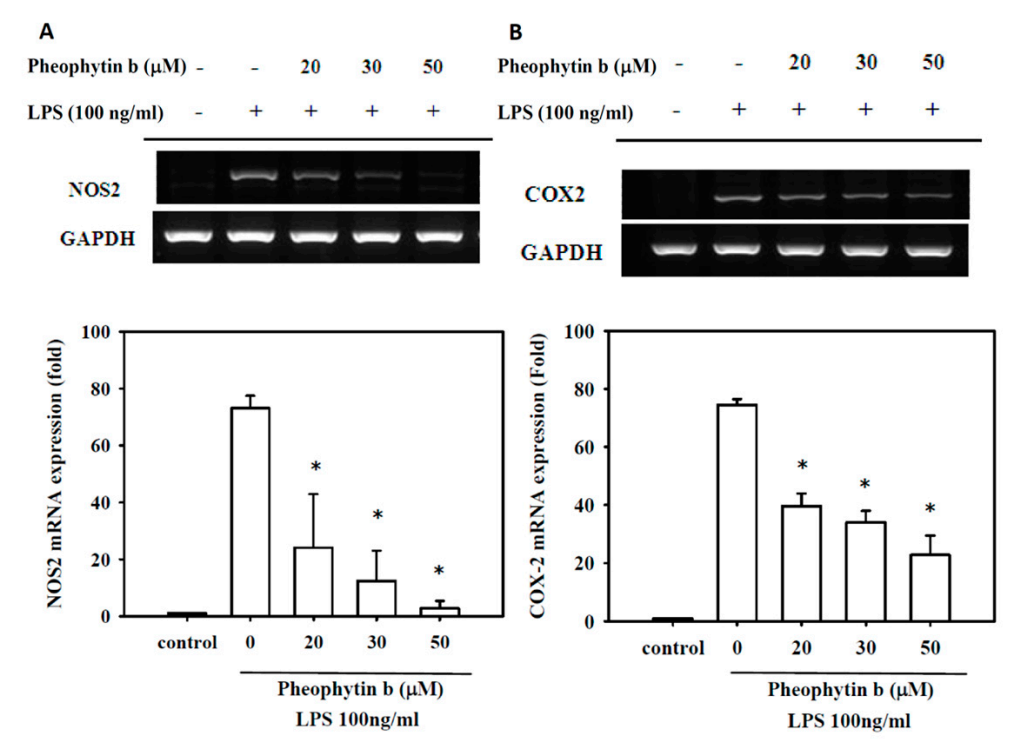

Figure 4. Pheophytin-b suppressed NOS2 and COX-2 mRNA expression levels in LPS-stimulated RAW 264.7 cells. Cells were pre-treated with the indicated concentrations of pheophytin-b for $30 \mathrm{~min}$ and stimulated with LPS for $3 \mathrm{~h}$. NOS2 (A) and COX-2 (B) mRNA levels were determined by QRT-PCR analysis, quantified, and normalized to those of the control group. Bottom panels show the fold-change compared to the control group (without LPS stimulation). Expression of GAPDH was analyzed as a control to ensure equal loading. ${ }^{*} p<0.05$ vs. the cells treated with LPS alone (by Student's $t$-test, $n=3)$. 
TNF- $\alpha$

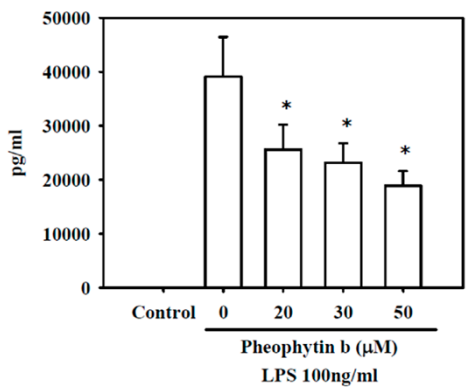

IL-1 $\beta$

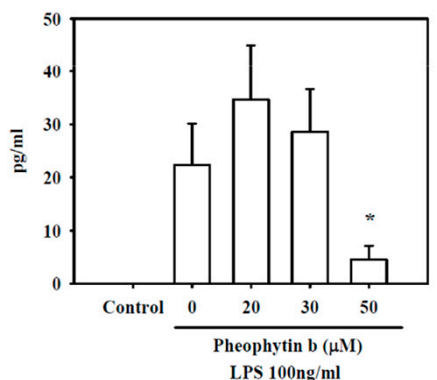

IL-6

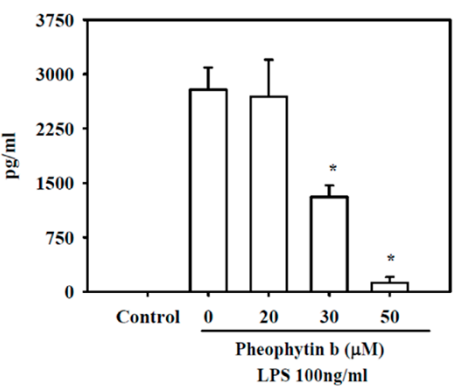

IL-10

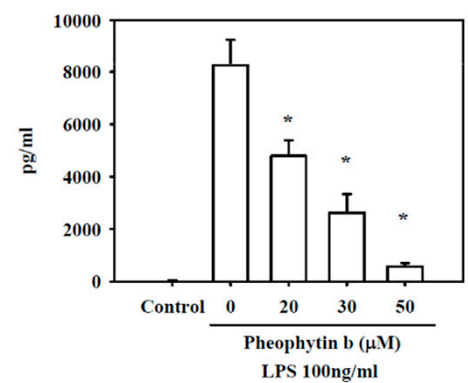

Figure 5. Pheophytin-b ameliorates cytokine expression induced by LPS in RAW 264.7 cells. RAW 264.7 cells were pre-treated with the indicated concentrations of pheophytin-b for $30 \mathrm{~min}$ followed by LPS $(100 \mathrm{ng} / \mathrm{mL})$ treatment for $24 \mathrm{~h}$. TNF- $\alpha$, IL-1 $\beta$, IL- 6 , and IL-10 concentrations were measured in the culture supernatants by ELISA. Results show the means \pm SEM of three experiments. ${ }^{*} p<0.05$ vs. cells treated with LPS alone (by Student's $t$-test, $n=3$ ).

A

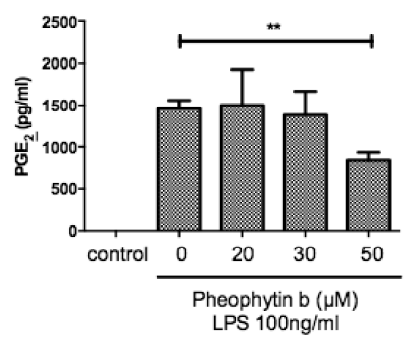

B

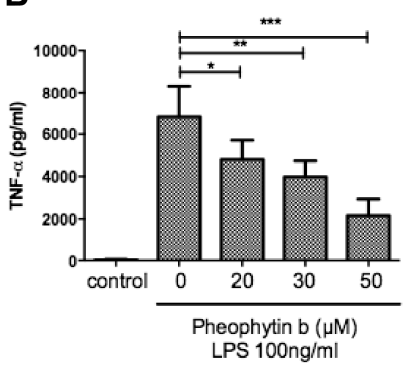

C

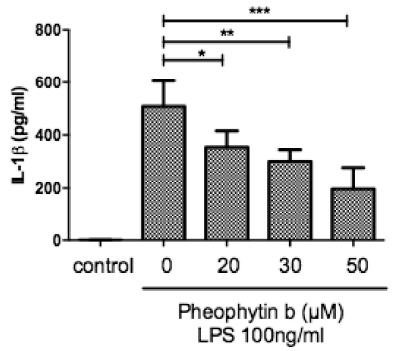

Figure 6. Cont. 

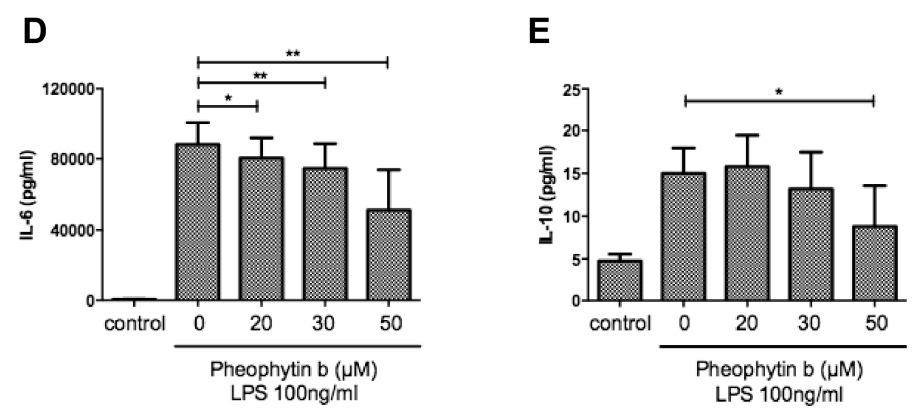

Figure 6. Effects of pheophytin-b on LPS-induced PGE2 and cytokine expression profiles by human $\mathrm{CD} 14^{+}$monocyte-derived macrophages. Human $\mathrm{CD}_{1} 4^{+}$monocyte-derived macrophages were pre-treated with the indicated concentrations of pheophytin-b for $30 \mathrm{~min}$ followed by LPS $(100 \mathrm{ng} / \mathrm{mL})$ for $24 \mathrm{~h}$. The secretions of PGE2 (A), TNF- $\alpha$ (B), IL-1 $\beta$ (C), IL-6 (D), and IL-10 (E) from LPS-induced cells pre-treated with/without pheophytin-b were measured. Results show the means \pm standard deviation of three experiments. ${ }^{*} p<0.05,{ }^{* *} p<0.01,{ }^{* * *} p<0.001$ vs. cells treated with LPS alone (Student's $t$-test, $n=3$ ).

\subsection{Effects of Pheophytin-b on LPS-Mediated Signal Transduction Pathways in Macrophages}

We next investigated the regulatory mechanism and pathway responsible for the suppression of inflammation in LPS-stimulated RAW 264.7 cells by first examining the expression of transcription factors and activation of signal transduction pathways. NF-KB has an important role in the induction of inflammation $[25,26]$; therefore, we examined the nuclear translocation of phosphorylated-p65 (p-p65) and cytoplasmic IkB $\alpha$. As shown in Figure S2, there was no significant change in p-p65 translocation or IkB $\alpha$ expression in response to pheophytin-b treatment in LPS-stimulated RAW 264.7 cells.

Another transcription factor that might bind to the NOS2 promoter is AP-1 [27], which related pathway includes c-Jun and c-Fos [28]. In addition, several signal transduction pathways, such as MAPKs and Akt, have also been demonstrated to be involved in regulating the sepsis-induced production of $\mathrm{NO}$ and pro-inflammatory cytokines and chemokines $[14,29,30]$. Hence, we investigated the activity of several MAPK pathway members, including phosphorylated p38, ERK1/2, and JNK; however, pheophytin-b had no significant inhibitory effect on these pathways (Figure S3). There were also no significant effects of pheophytin-b on the c-Fos and c-Jun pathways in LPS-stimulated RAW 264.7 cells (Figure S4). In contrast, $30 \mu \mathrm{M}$ pheophytin-b significantly suppressed the levels of phosphorylated STAT1 (p-STAT1), PI3K (p-PI3K), and Akt (p-Akt), which stimulated by LPS (Figure 7).
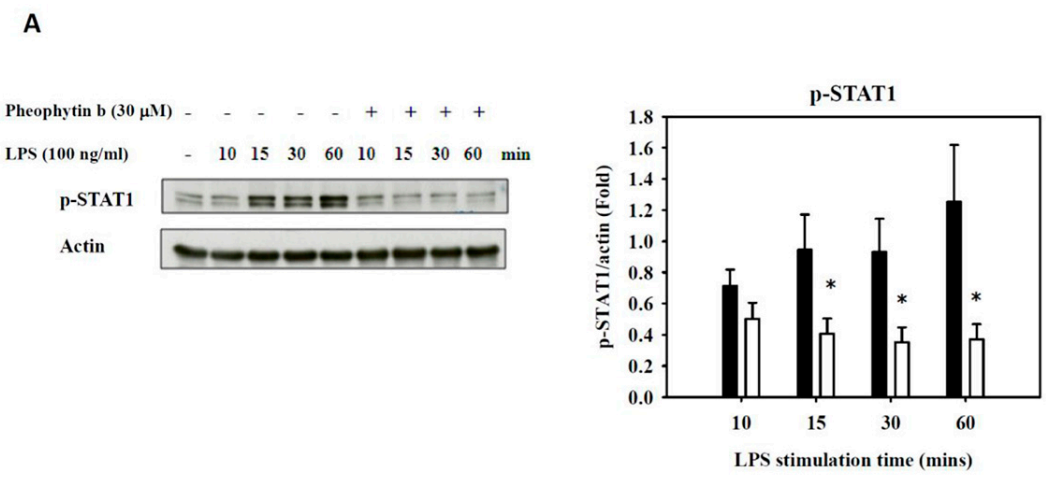

Figure 7. Cont. 
B
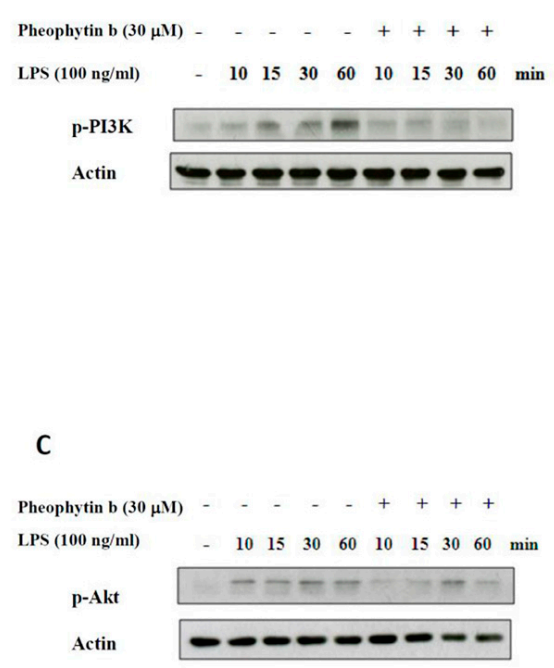
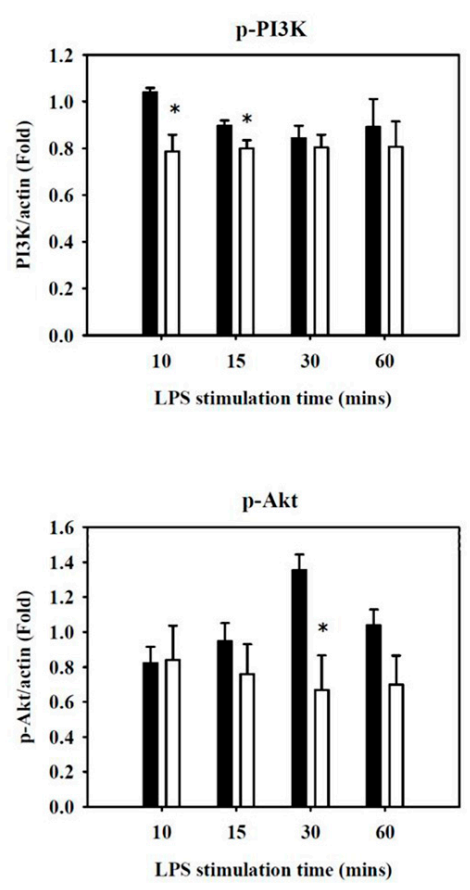

Pheophytin b $0(\mu \mathrm{M})$ Pheophytin b $30(\mu \mathrm{M})$

Figure 7. Effects of pheophytin-b on the STAT1 and PI3K/Akt pathways in LPS-stimulated RAW 264.7 cells. Western blot analysis of STAT1 (A), PI3K (B), and Akt (C) phosphorylation induced by LPS (100 ng/mL) was significantly suppressed by pheophytin-b. Cells were pre-treated with $30 \mu \mathrm{M}$ pheophytin-b for $30 \mathrm{~min}$, and total protein was harvested at four different time points $(10,15,30$ and $60 \mathrm{~min}$ ) after LPS stimulation $(100 \mathrm{ng} / \mathrm{mL}) .{ }^{*} p<0.05 \mathrm{vs}$. cells treated with LPS alone (Student's $t$-test, $n=3$ ).

\section{Discussion}

Sepsis is a lethal host response to a microbial infection, and its high mortality rate is related to a dysregulation of inflammatory mediators. Therefore, a possible therapeutic approach to sepsis treatment may focus on anti-inflammatory agents to suppress the proinflammatory cytokine storm. The importance of natural products for disease treatment and drug discovery was again recently emphasized and highlighted in the 2015 Nobel Prize in Medicine [31]. We previously reported that the chlorophyll-related compound, pheophytin-a, suppresses LPS-induced NOS-2, PGE2, and IL-1 $\beta$ production by macrophages [20]. Here, in this study, we present evidence that pheophytin-b also possesses similar anti-inflammatory effects on LPS-stimulated murine macrophages (RAW264.7) and human $\mathrm{CD} 14^{+}$monocyte-derived macrophages without inducing cytotoxicity. Both NO and PGE2 end products were reduced with pheophytin- $b$, in addition to both mRNA and protein of the NOS-2 and COX-2 in a dose-dependent manner.

Compared to pheophytin-a, pheophytin-b is more tolerable to cells [20]. Specifically, RAW 264.7 cell proliferation was significantly reduced when the dose of pheophytin-a was titrated up to $25 \mu \mathrm{M}$ [20]. In contrast, even the treatment concentrations of pheophytin-b were increased up to $50 \mu \mathrm{M}$, there were no significant cytotoxicity effects on both the RAW 264.7 cells and the human CD14 ${ }^{+}$monocyte-derived macrophages. These results suggested that pheophytin-b may have a larger "therapeutic range" than pheophytin-a. The differential cytotoxicities observed between pheophytin-a and pheophytin-b may be mediated by diverging cell signaling regulation. Although both molecules suppressed the STAT-1 pathway without influencing NF- $\mathrm{KB}$ or AP-1 signaling [20], pheophytin-a specifically increased ERK1/2 activity. In contrast, no changes in MAPK signaling (phosphorylated p38, ERK1/2, and JNK) 
were observed with pheophytin-b. Further studies are required to examine the specific cellular pathways underlying pheophytin-a-induced cytotoxicity.

Unlike the anti-inflammatory activity observed for the edible brown alga Saccharina japonica and its constituents [32], pheophytin-b decreased COX-2 expression in both RAW 264.7 cells and $\mathrm{CD} 14^{+}$monocyte-derived macrophages. Our findings also suggest that pheophytin-b significantly suppresses NOS-2 expression at both the transcriptional and translational levels in LPS-stimulated RAW 264.7 cells. Although NO production from human $\mathrm{CD}^{+} 4^{+}$monocyte-derived macrophages is difficult to detect [24,33], we did discern a suppression of nitrite production with pheophytin-b. Moreover, the inhibitory effect of pheophytin-b on the inflammatory response was evident in the significant suppression of LPS-induced PGE2, TNF- $\alpha$, IL-1 $\beta$, IL-6, and IL-10 by macrophages.

IL-10, which is thought to be an anti-inflammatory cytokine, was also suppressed by pheophytin-b, which is similar to that observed for other compounds, including synthetic chalcone and flavone derivatives, wogonin, and phenylpropanoid dimers isolated from Nectandra leucantha [34-38]. A possible explanation is that, when pheophytin-b inhibits inflammation, the subsequent production of an anti-inflammatory cytokine, such as IL-10, can be lessened to a degree that corresponds to the decrease in inflammatory cytokine production.

Inhibition of pathophysiological NO has been suggested to be a therapeutic target in sepsis although several clinical studies have been prematurely terminated due to the absence of therapeutic benefits [13]. The promoter of the NOS2 gene, which is responsible for excessive NO production in sepsis in response to LPS [12], can be bound by several transcriptional factors, such as NF- $\mathrm{kB}$, AP-1, and STAT-1 [39-41]. In addition, the PI3K and Akt pathways also play an important role in the production of NO under LPS simulation [42]. In the present study, pheophytin-b exerted its anti-inflammatory effect via PI3K, Akt, and the subsequent STAT-1 pathway. However, no activation of the NF- $\kappa$ B or MAPK pathways was observed with pheophytin-b. Figure 8 illustrates our proposed scheme depicting the immune-modulatory mechanism of pheophytin-b. In a mechanism similar to that reported for 6-dehydrogingerdione, a component of ginger [43], as well as the flavonoids, phloretin and phorizin [14], pheophytin-b suppressed LPS-induced STAT1, PI3K, and Akt activation, resulting in a reduction in cytokines, NO, and PGE2 production.

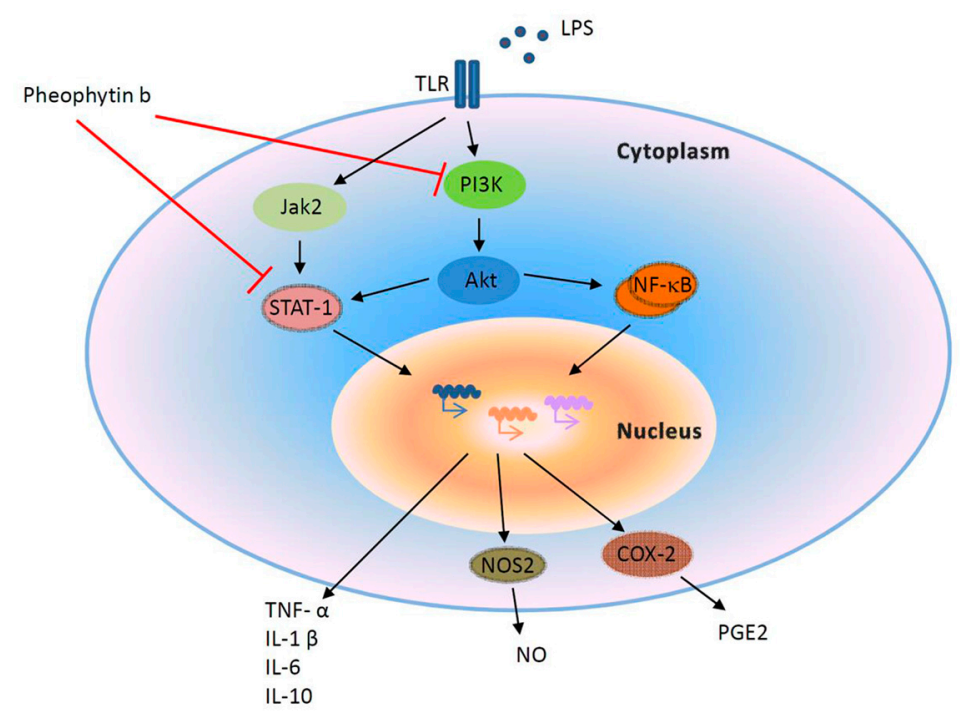

Figure 8. Proposed mechanism depicting the effect of pheophytin-b on LPS-stimulated macrophages. Production of NO, PGE2, IL-1 $\beta$, IL-6, IL-10, and TNF- $\alpha$ induced by LPS are suppressed by pheophytin-b inhibition of STAT-1 and PI3K/Akt signaling pathways.

In conclusion, pheophytin-b has potent anti-inflammatory effects in LPS-stimulated macrophages. Therefore, this compound could represent a potential agent for use as an immunomodulatory drug for 
patients with sepsis. In subsequent experiments, pheophytin-b has shown rare activity that would interfere with the phagocytosis of human macrophages (data not shown). Further in vivo analyses are required to fully examine the impact of pheophytin-b on sepsis.

\section{Materials and Methods}

\subsection{Reagents and Antibodies}

Pheophytin-b was purchased from Wako Pure Chemical Industries, Ltd., Osaka, Japan. LPS (Escherichia coli O26:B6, L2654) was purchased from Sigma (St. Louis, MO, USA).

The NOS2 antibody was purchased from BD Biosciences (San Jose, CA, USA). Antibodies against p44/p42 MAP Kinase (Thr202/Tyr204), p38 MAP Kinase (Thr180/Tyr182), SAPK/JNK (Thr183/Tyr185), ERK1/2 MAP Kinase (Thr202/Tyr204), phospho-IkB- $\alpha$ (Ser32/36), STAT1 (Tyr701), Akt (Ser473), PI3K p85 (Tyr458)/p55 (Tyr199), c-Fos (9F6), c-Jun (Ser73), and COX-2 were all purchased from Cell Signaling (Danvers, MA, USA). The NF-kB p65 rabbit monoclonal antibody (Cell Signaling), lamin B antibody (Santa Cruz, CA, USA), and mouse monoclonal beta-Actin antibody (Abcam, Cambridge, MA, USA) were also utilized.

\subsection{RAW 264.7 Cell Culture}

RAW 264.7 cells, derived from murine macrophages, were purchased from the Bioresource Collection and Research Center (BCRC, Hsinchu, Taiwan). RAW 264.7 cells were cultured in DMEM (GIBCO, Carlsbad, CA, USA) with 10\% heat-inactivated fetal bovine serum (Biological Industries, Cromwell, CT, USA), $100 \mathrm{U} / \mathrm{mL}$ penicillin, $100 \mu \mathrm{g} / \mathrm{mL}$ streptomycin, $25 \mu \mathrm{g} / \mathrm{mL}$ amphotericin B (Biological Industries), and $2 \mathrm{mM}$ L-glutamine (GIBCO). The cells were culture in a $37^{\circ} \mathrm{C}$ incubator with $5 \% \mathrm{CO}_{2}$.

\subsection{Ex Vivo Isolation of Human CD14 ${ }^{+}$Monocytes and Stimulation into Macrophages}

This project has been approved by the Institutional Review Board of Kaohsiung Medical University Hospital (KMUH-IRB-20140303). Human CD14 ${ }^{+}$monocytes were isolated from human peripheral blood mononuclear cells (PBMCs) obtained from blood buffy coats according to the methods previously described [44,45]. In brief, $20 \mathrm{~mL}$ of each blood sample was collected into aseptic tubes containing EDTA from the veins of three healthy volunteers for independent experiments. PBMCs were isolated by gradient centrifugation on Ficoll-Hypaque (GE Healthcare, Wauwatosa, WI, USA) with anti-CD14 microbeads (Miltenyi Biotec $\mathrm{GmbH}$, Bergisch Gladbach, Germany), according to the manufacturer's instructions. Cells were washed twice with PBS and resuspended in RPMI 1640 medium (Mediatech, Manassas, VA, USA) supplemented with $10 \% \mathrm{FBS}$ and antibiotics $(100 \mathrm{U} / \mathrm{mL}$ penicillin, $100 \mu \mathrm{g} / \mathrm{mL}$ streptomycin, and $0.25 \mathrm{~g} / \mathrm{mL}$ Amphotericin B). For purity examination, CD14 ${ }^{+}$cells were labeled with CD14-FITC and CD3-PE and analyzed by flow cytometry. PBMCs were used as a control. CD14 ${ }^{+}$ positive cells showed $>95 \%$ of purity (refer to Figure S1 and see below). We then stimulated the purified human $\mathrm{CD} 14^{+}$monocytes to differentiate into macrophages by adding human GM-CSF $(10 \mathrm{ng} / \mathrm{mL})$ (PeproTech, Rocky Hill, NJ, USA) for 6 days at $37^{\circ} \mathrm{C}$ in $5 \% \mathrm{CO}_{2}[46]$ after which they were prepared for subsequent pheophytin-b treatment.

\subsection{Cytotoxicity Analysis Following Pheophytin-b Treatment}

Cytotoxicity analyses following stimulation with pheophytin-b were evaluated in both types of macrophages using an Alamar Blue Cell viability kit (Serotec Ltd. Scandinavia, Hamar, Norway). In brief, $200 \mu \mathrm{L}$ of $10 \%$ Alamar Blue reagent was added into a 96-well plate, containing $2 \times 10^{4}$ cells/well and $200 \mu \mathrm{L}$ of medium, the cells of which were treated with $0,20,30$, and $50 \mu \mathrm{M}$ pheophytin-b for $24 \mathrm{~h}$. Colorimetric analyses were obtained with an ELISA plate reader at 570 and $600 \mathrm{~nm}$, and the cytotoxicity of pheophytin-b treatment was evaluated relative to controls. 
4.5. Western Blot and QRT-PCR Analysis of NO2 and COX-2 Protein in Pheophytin-b Treatment and LPS Stimulation of RAW 264.7 Cells

RAW 264.7 cells were treated with the indicated concentrations of pheophytin-b. After $30 \mathrm{~min}$, the cells were stimulated with LPS $(100 \mathrm{ng} / \mathrm{mL})$. After $3 \mathrm{~h}$, the cells were collected and prepared for real-time quantitative PCR (QRT-PCR) analysis [20,47]. After $6 \mathrm{~h}$, the cells were collected to measure NOS2 and COX-2 protein production by Western blot analysis. Expression of actin was analyzed as a control to ensure equal loading. For QRT-PCR, the mRNA was extracted from RAW 264.7 cells using the RNAspin Mini RNA Isolation Kit (GE Healthcare, Buckinghamshire, UK). QRT-PCR analysis measuring NOS2 and COX-2 mRNA levels was then performed in a Roche LightCycler (Mannheim, Germany), based on a method previously described [43]. Primers used for PCR were as follows: NOS2 forward primer, 5'-CCCTTCCGAAGTTTCTGGCAGCAGC-3 ${ }^{\prime}$ and reverse primer, 5'-GGCTGTCAGAGAGCCTCGTGGCTTTGG-3'; COX-2 forward primer, 5'-CATTGATG GTGGCTGTTTTG-3' and reverse primer, 5'-GTTGCTGGGGGAAGAAATGT-3'; GAPDH forward primer, $5^{\prime}$-TCCACCACCCTGTTGCTGTA- $3^{\prime}$ and reverse primer, $5^{\prime}$-ACCACAGTCCATGCCATCAC- $3^{\prime}$.

\subsection{Measurement of Nitrite Release Indicative of NO Production}

The concentration of nitrite, a stable metabolite of NO, in the supernatant has been measured as an indicator of NO production [39] using the Griess reagent system (Promega Biotech Co., Ltd., Madison, WI, USA) according to the manufacturer's instructions. In brief, cells were treated with various doses of pheophytin-b and LPS after which $50 \mu \mathrm{L}$ of each supernatant was carefully transferred into a 96-well plate, and $50 \mu \mathrm{L}$ of Griess reagent was subsequently added. In the Griess reagent system, nitrite standard $(0.1 \mathrm{M}$ sodium nitrite) was prepared for a reference curve from the concentration of $100 \mu \mathrm{M}$ to that of $1.56 \mu \mathrm{M}$. After color development for $10 \mathrm{~min}$, absorbance was measured at a wavelength of $520 \mathrm{~nm}$. This absorbance was then normalized using the standard curve to obtain the nitrite concentration.

\subsection{Transcription Factor (NF- $\kappa B$ and AP-1) Translocation Assays}

Cytosolic and nuclear extracts were isolated from RAW 264.7 cells according to a previously described protocol [43]. In brief, cytosolic and nuclear proteins were harvested 10, 15, 30, and 60 min after LPS stimulation, based on the method previously described [20].

\subsection{Enzyme-Linked Immunosorbent Assay (ELISA) Analyses}

RAW 264.7 cells were plated at a density of $4 \times 10^{5}$ cells per well in 12 -well plates. After the cells were pre-treated with different concentrations of pheophytin-b, they were treated with LPS, and the supernatants were collected after $16 \mathrm{~h}$ for detection of PGE2 or $24 \mathrm{~h}$ for cytokines. PGE2 protein concentrations were measured using ELISA kits for PGE2 (R\&D Systems, Minneapolis, MN, USA); TNF- $\alpha$, IL-1 $\beta$, IL-6, and IL-10 levels were measured using ELISA kits from eBioscience (San Diego, CA, USA). Each treatment was performed in duplicate wells, and at least three parallel experiments were performed.

\subsection{Signal Transduction Pathway Analysis}

Nuclear translocation of components of the NF- $\kappa$ B pathway ( $\operatorname{IkB} \alpha$ and $\mathrm{p} 65)$ and phosphorylation of the MAPK pathway (i.e., p38, ERK1/2, and JNK), c-Fos, c-Jun, STAT-1, PI3K, and Akt proteins were analyzed in RAW 264.7 cells pretreated with pheophytin-b for $30 \mathrm{~min}$ followed by induction with LPS $(100 \mathrm{ng} / \mathrm{mL})$. Total and nuclear proteins were harvested at 10, 15, 30, and $60 \mathrm{~min}$ after stimulation with LPS. Each experiment was repeated three times. 


\subsection{Statistical Analysis}

Experimental results are expressed as the means \pm standard errors of mean (SEM), unless otherwise specified as standard deviations (SD), with $n$ indicating the number of experiments. Statistical significance was determined by Student's $t$-test. All differences were considered significant at a $p$-value of $<0.05$.

Supplementary Materials: The following are available online at www.mdpi.com/1422-0067/18/12/2637/s1.

Author Contributions: Yen-Hsu Chen is the guarantor of integrity of the entire study. Chun-Yu Lin, Wen-Hung Wang, Shin-Huei Chen, Chung-Yi Chen, and Yen-Hsu Chen made substantial contributions to the conception and design of the work. Chun-Yu Lin, Shin-Huei Chen, Yu-Wei Chang, and Ling-Chien Hung conceived and designed the experiments; Chun-Yu Lin, Shin-Huei Chen, Yu-Wei Chang, and Ling-Chien Hung performed the experiments; Chun-Yu Lin, Shin-Huei Chen, Yu-Wei Chang, and Ling-Chien Hung acquired and analyzed the data; Chun-Yu Lin, Wen-Hung Wang, and Shin-Huei Chen drafted the paper. Yen-Hsu Chen edited and reviewed the paper. All authors have read and approved the final version to be submitted.

Conflicts of Interest: The authors declare no conflict of interest.

Funding: The study was supported by the following grants: MOST 104-2320-B-037-004 to Yen-Hsu Chen, MOST 103-2314-B-037-068 to Chun-Yu Lin, KMUH101-1M15 to Chun-Yu Lin and KMUH103-3T05 to Chun-Yu Lin.

$\begin{array}{ll}\text { Abbreviations } \\ \text { COX-2 } & \text { cyclooxygenase-2 } \\ \text { ELISA } & \text { enzyme-linked immunosorbent assay } \\ \text { IL } & \text { interleukin } \\ \text { LPS } & \text { lipopolysaccharide } \\ \text { NO } & \text { nitric oxide } \\ \text { NOS2 } & \text { NO synthase } 2 \\ \text { PGE2 } & \text { prostaglandin E2 } \\ \text { QRT-PCR } & \text { real-time quantitative PCR } \\ \text { SD } & \text { standard deviations } \\ \text { SEM } & \text { standard errors of mean } \\ \text { TNF- } \alpha & \text { tumor necrosis factor- } \alpha\end{array}$

\section{References}

1. Martin, G.S.; Mannino, D.M.; Eaton, S.; Moss, M. The epidemiology of sepsis in the United States from 1979 through 2000. N. Engl. J. Med. 2003, 348, 1546-1554. [CrossRef] [PubMed]

2. Seymour, C.W.; Rea, T.D.; Kahn, J.M.; Walkey, A.J;; Yealy, D.M.; Angus, D.C. Severe sepsis in pre-hospital emergency care: Analysis of incidence, care, and outcome. Am. J. Respir. Crit. Care Med. 2012, 186, 1264-1271. [CrossRef] [PubMed]

3. Angus, D.C.; Van der Poll, T. Severe sepsis and septic shock. N. Engl. J. Med. 2013, 369, 840-851. [CrossRef] [PubMed]

4. Bleiblo, F.; Michael, P.; Brabant, D.; Ramana, C.V.; Tai, T.; Saleh, M.; Parrillo, J.E.; Kumar, A.; Kumar, A. The role of immunostimulatory nucleic acids in septic shock. Int. J. Clin. Exp. Med. 2012, 5, 1-23. [PubMed]

5. Lin, C.Y.; Chen, T.C.; Lu, P.L.; Chen, H.J.; Bojang, K.S.; Chen, Y.H. Lower initial central venous pressure in septic patients from long-term care facilities than in those from the community. J. Microbiol. Immunol. Infect. 2014, 47, 422-428. [CrossRef] [PubMed]

6. Linde-Zwirble, W.T.; Angus, D.C. Severe sepsis epidemiology: Sampling, selection, and society. Crit. Care 2004, 8, 222-226. [CrossRef] [PubMed]

7. Gasparrini, M.; Forbes-Hernandez, T.Y.; Giampieri, F.; Afrin, S.; Alvarez-Suarez, J.M.; Mazzoni, L.; Mezzetti, B.; Quiles, J.L.; Battino, M. Anti-inflammatory effect of strawberry extract against LPS-induced stress in RAW 264.7 macrophages. Food Chem. Toxicol. 2017, 102, 1-10. [CrossRef] [PubMed] 
8. Mazzio, E.A.; Li, N.; Bauer, D.; Mendonca, P.; Taka, E.; Darb, M.; Thomas, L.; Williams, H.; Soliman, K.F. Natural product HTP screening for antibacterial (E. coli 0157:H7) and anti-inflammatory agents in (LPS from E. coli O111:B4) activated macrophages and microglial cells; focus on sepsis. BMC Complement. Altern. Med. 2016, 16, 467. [CrossRef] [PubMed]

9. Chaudhry, H.; Zhou, J.; Zhong, Y.; Ali, M.M.; McGuire, F.; Nagarkatti, P.S.; Nagarkatti, M. Role of cytokines as a double-edged sword in sepsis. In Vivo 2013, 27, 669-684. [PubMed]

10. Russell, J.A. Management of sepsis. N. Engl. J. Med. 2006, 355, 1699-1713. [CrossRef] [PubMed]

11. Cavaillon, J.M.; Adib-Conquy, M. Monocytes/macrophages and sepsis. Crit. Care Med. 2005, 33 (Suppl. S12), S506-S509. [CrossRef] [PubMed]

12. Hiroi, M.; Sakaeda, Y.; Yamaguchi, H.; Ohmori, Y. Anti-inflammatory cytokine interleukin-4 inhibits inducible nitric oxide synthase gene expression in the mouse macrophage cell line RAW264.7 through the repression of octamer-dependent transcription. Mediat. Inflamm. 2013, 2013, 369693. [CrossRef] [PubMed]

13. Lupp, C.; Baasner, S.; Ince, C.; Nocken, F.; Stover, J.F.; Westphal, M. Differentiated control of deranged nitric oxide metabolism: A therapeutic option in sepsis? Crit. Care 2013, 17, 311. [CrossRef] [PubMed]

14. Chang, W.T.; Huang, W.C.; Liou, C.J. Evaluation of the anti-inflammatory effects of phloretin and phlorizin in lipopolysaccharide-stimulated mouse macrophages. Food Chem. 2012, 134, 972-979. [CrossRef] [PubMed]

15. Kumar, A.; Thota, V.; Dee, L.; Olson, J.; Uretz, E.; Parrillo, J.E. Tumor necrosis factor alpha and interleukin 1beta are responsible for in vitro myocardial cell depression induced by human septic shock serum. J. Exp. Med. 1996, 183, 949-958. [CrossRef] [PubMed]

16. Kumar, A.; Brar, R.; Wang, P.; Dee, L.; Skorupa, G.; Khadour, F.; Schulz, R.; Parrillo, J.E. Role of nitric oxide and cGMP in human septic serum-induced depression of cardiac myocyte contractility. Am. J. Physiol. 1999, 276, R265-R276. [PubMed]

17. Zhang, H.; Wang, H.Y.; Bassel-Duby, R.; Maass, D.L.; Johnston, W.E.; Horton, J.W.; Tao, W. Role of interleukin-6 in cardiac inflammation and dysfunction after burn complicated by sepsis. Am. J. Physiol. Heart Circ. Physiol. 2007, 292, H2408-H2416. [CrossRef] [PubMed]

18. Zhong, Y.; Chiou, Y.S.; Pan, M.H.; Shahidi, F. Anti-inflammatory activity of lipophilic epigallocatechin gallate (EGCG) derivatives in LPS-stimulated murine macrophages. Food Chem. 2012, 134, 742-748. [CrossRef] [PubMed]

19. Murakami, A.; Ohigashi, H. Targeting NOX, INOS and COX-2 in inflammatory cells: Chemoprevention using food phytochemicals. Int. J. Cancer 2007, 121, 2357-2363. [CrossRef] [PubMed]

20. Lin, C.Y.; Lee, C.H.; Chang, Y.W.; Wang, H.M.; Chen, C.Y.; Chen, Y.H. Pheophytin a inhibits inflammation via suppression of LPS-induced nitric oxide synthase-2, prostaglandin E2, and interleukin-1beta of macrophages. Int. J. Mol. Sci. 2014, 15, 22819-22834. [CrossRef] [PubMed]

21. Higashi-Okai, K.; Otani, S.; Okai, Y. Potent suppressive activity of pheophytin a and b from the non-polyphenolic fraction of green tea (Camellia sinensis) against tumor promotion in mouse skin. Cancer Lett. 1998, 129, 223-228. [CrossRef]

22. Okai, Y.; Higashi-Okai, K. Potent suppressing activity of the non-polyphenolic fraction of green tea (Camellia sinensis) against genotoxin-induced umu C gene expression in Salmonella typhimurium (TA 1535/pSK 1002)—Association with pheophytins a and b. Cancer Lett. 1997, 120, 117-123. [CrossRef]

23. Higashi-Okai, K.; Yamazaki, M.; Nagamori, H.; Okai, Y. Identification and antioxidant activity of several pigments from the residual green tea (Camellia sinensis) after hot water extraction. J. UOEH 2001, 23, 335-344. [CrossRef] [PubMed]

24. Weinberg, J.B.; Misukonis, M.A.; Shami, P.J.; Mason, S.N.; Sauls, D.L.; Dittman, W.A.; Wood, E.R.; Smith, G.K.; McDonald, B.; Bachus, K.E. Human mononuclear phagocyte inducible nitric oxide synthase (iNOS): Analysis of iNOS mRNA, iNOS protein, biopterin, and nitric oxide production by blood monocytes and peritoneal macrophages. Blood 1995, 86, 1184-1195. [PubMed]

25. Tammi, R.H.; Passi, A.G.; Rilla, K.; Karousou, E.; Vigetti, D.; Makkonen, K.; Tammi, M.I. Transcriptional and post-translational regulation of hyaluronan synthesis. FEBS J. 2011, 278, 1419-1428. [CrossRef] [PubMed]

26. Ruland, J. Return to homeostasis: Downregulation of NF-kappaB responses. Nat. Immunol. 2011, 12, 709-714. [CrossRef] [PubMed]

27. Pautz, A.; Art, J.; Hahn, S.; Nowag, S.; Voss, C.; Kleinert, H. Regulation of the expression of inducible nitric oxide synthase. Nitric Oxide 2010, 23, 75-93. [CrossRef] [PubMed] 
28. Hess, J.; Angel, P.; Schorpp-Kistner, M. AP-1 subunits: Quarrel and harmony among siblings. J. Cell Sci. 2004, 117, 5965-5973. [CrossRef] [PubMed]

29. Cargnello, M.; Roux, P.P. Activation and function of the MAPKs and their substrates, the MAPK-activated protein kinases. Microbiol. Mol. Biol. Rev. 2011, 75, 50-83. [CrossRef] [PubMed]

30. Yoshimura, A.; Naka, T.; Kubo, M. SOCS proteins, cytokine signalling and immune regulation. Nat. Rev. Immunol. 2007, 7, 454-465. [CrossRef] [PubMed]

31. Croft, S.L.; Ward, S. The Nobel Prize in Medicine 2015: Two drugs that changed global health. Sci. Transl. Med. 2015, 7, 316ed14. [CrossRef] [PubMed]

32. Islam, M.N.; Ishita, I.J.; Jin, S.E.; Choi, R.J.; Lee, C.M.; Kim, Y.S.; Jung, H.A.; Choi, J.S. Anti-inflammatory activity of edible brown alga Saccharina japonica and its constituents pheophorbide a and pheophytin a in LPS-stimulated RAW 264.7 macrophage cells. Food Chem. Toxicol. 2013, 55, 541-548. [CrossRef] [PubMed]

33. Denis, M. Human monocytes/macrophages: NO or no NO? J. Leukoc. Biol. 1994, 55, 682-684. [PubMed]

34. Mateeva, N.; Gangapuram, M.; Mazzio, E.; Eyunni, S.; Soliman, K.F.; Redda, K.K. Biological evaluation of synthetic chalcone and flavone derivatives as anti-inflammatory agents. Med. Chem. Res. 2015, 24, 1672-1680. [CrossRef] [PubMed]

35. Lee, J.Y.; Park, W. Anti-Inflammatory Effect of Wogonin on RAW 264.7 Mouse Macrophages Induced with Polyinosinic-Polycytidylic Acid. Molecules 2015, 20, 6888-6900. [CrossRef] [PubMed]

36. Da Costa-Silva, T.A.; Grecco, S.S.; de Sousa, F.S.; Lago, J.H.; Martins, E.G.; Terrazas, C.A.; Varikuti, S.; Owens, K.L.; Beverley, S.M.; Satoskar, A.R.; et al. Immunomodulatory and Antileishmanial Activity of Phenylpropanoid Dimers Isolated from Nectandra leucantha. J. Nat. Prod. 2015, 78, 653-657. [CrossRef] [PubMed]

37. Menk, M.; Graw, J.A.; von Haefen, C.; Sifringer, M.; Schwaiberger, D.; Unger, T.; Steckelings, U.; Spies, C.D. Stimulation of the Angiotensin II AT2 Receptor is Anti-inflammatory in Human Lipopolysaccharide-Activated Monocytic Cells. Inflammation 2015, 38, 1690-1699. [CrossRef] [PubMed]

38. Sayed, R.H.; Khalil, W.K.; Salem, H.A.; Kenawy, S.A.; El-Sayeh, B.M. Sulforaphane increases the survival rate in rats with fulminant hepatic failure induced by D-galactosamine and lipopolysaccharide. Nutr. Res. 2014, 34, 982-989. [CrossRef] [PubMed]

39. Green, L.C.; Wagner, D.A.; Glogowski, J.; Skipper, P.L.; Wishnok, J.S.; Tannenbaum, S.R. Analysis of nitrate, nitrite, and $\left[{ }^{15} \mathrm{~N}\right]$ nitrate in biological fluids. Anal. Biochem. 1982, 126, 131-138. [CrossRef]

40. Chen, C.C.; Wang, J.K. p38 but not p44/42 mitogen-activated protein kinase is required for nitric oxide synthase induction mediated by lipopolysaccharide in RAW 264.7 macrophages. Mol. Pharmacol. 1999, 55, 481-488. [PubMed]

41. Kleinert, H.; Pautz, A.; Linker, K.; Schwarz, P.M. Regulation of the expression of inducible nitric oxide synthase. Eur. J. Pharmacol. 2004, 500, 255-266. [CrossRef] [PubMed]

42. Rhee, S.H.; Jones, B.W.; Toshchakov, V.; Vogel, S.N.; Fenton, M.J. Toll-like receptors 2 and 4 activate STAT1 serine phosphorylation by distinct mechanisms in macrophages. J. Biol. Chem. 2003, 278, 22506-22512. [CrossRef] [PubMed]

43. Huang, S.H.; Lee, C.H.; Wang, H.M.; Chang, Y.W.; Lin, C.Y.; Chen, C.Y.; Chen, Y.H. 6-Dehydrogingerdione restrains lipopolysaccharide-induced inflammatory responses in RAW 264.7 macrophages. J. Agric. Food Chem. 2014, 62, 9171-9179. [CrossRef] [PubMed]

44. Jaguin, M.; Houlbert, N.; Fardel, O.; Lecureur, V. Polarization profiles of human M-CSF-generated macrophages and comparison of M1-markers in classically activated macrophages from GM-CSF and M-CSF origin. Cell. Immunol. 2013, 281, 51-61. [CrossRef] [PubMed]

45. Van Grevenynghe, J.; Rion, S.; Le Ferrec, E.; Le Vee, M.; Amiot, L.; Fauchet, R.; Fardel, O. Polycyclic aromatic hydrocarbons inhibit differentiation of human monocytes into macrophages. J. Immunol. 2003, 170, 2374-2381. [CrossRef] [PubMed] 
46. Wu, M.F.; Chen, S.T.; Yang, A.H.; Lin, W.W.; Lin, Y.L.; Chen, N.J.; Tsai, I.S.; Li, L.; Hsieh, S.L. CLEC5A is critical for dengue virus-induced inflammasome activation in human macrophages. Blood 2013, 121, 95-106. [CrossRef] [PubMed]

47. Ohnishi, T.; Bandow, K.; Kakimoto, K.; Kusuyama, J.; Matsuguchi, T. Long-time treatment by low-dose $N$-acetyl-L-cysteine enhances proinflammatory cytokine expressions in LPS-stimulated macrophages. PLOS ONE 2014, 9, e87229. [CrossRef] [PubMed] 